\section{Influence of static and dynamic occlusal characteristics and muscle force on masticatory performance in dentate adults}

Lujan-Climent M, Martinez-Gomis J, Palau S, Ayuso-Montero R, Salsench J, Peraire $M$. Influence of static and dynamic occlusal characteristics and muscle force on masticatory performance in dentate adults. Eur J Oral Sci 2008; 116: 1-8. (C) 2008 The Authors. Journal compilation (C) 2008 Eur J Oral Sci

Masticatory performance is the outcome of a complex interplay of several factors. This study was carried out to determine the relationship between masticatory performance and several muscular-related and occlusion-related factors in a population with a full or near-full complement of natural teeth. One-hundred dentate young adults participated in this cross-sectional study. Maximum muscular force with jaw, hand, tongue, and cheek were measured by means of a gnatodynamometer. Occlusal contact area and number of teeth in contact were determined in the maximal intercuspal position and in a $1.5-\mathrm{mm}$ right and left lateral excursion by means of interocclusal registrations that were scanned and analysed using image software. Masticatory performance was determined by sieving the Optosil particles resulting from 20 chewing cycles. Stepwise multiple linear regression analysis showed that the maximum bite force in the region of the first molar had the best correlation with masticatory performance and explained $36 \%$ of its variation. Static occlusion characteristics such as occlusal contact area, the lack of lateral crossbite and the number of anterior teeth in contact explained an additional $9 \%$ of the variation in masticatory performance. These findings suggest that variables related to dynamic occlusion or tongue or cheek force do not enhance the prediction of masticatory performance.

\author{
Mar Lujan-Climent, Jordi Martinez- \\ Gomis, Sara Palau, Raul Ayuso- \\ Montero, Juan Salsench, Maria \\ Peraire
}

Department of Prosthodontics, Faculty of Dentistry, Universitat de Barcelona, Barcelona, Spain

\section{Dr Jordi Martínez-Gomis, Campus de Bellvitge Universitat de Barcelona, C/ Feixa llarga s/n,} 08907 L'Hospitalet de Llobregat, Spain

Telefax: +34-934-035558

E-mail: jmartinezgomis@ub.edu

Key words: bite force; chewing efficiency; mastication; occlusion

Accepted for publication January 2008
Masticatory function is evaluated by self-assessments of chewing ability and/or objective masticatory perfor2 mance determined using laboratory tests (1). Masticatory performance can be determined by quantifying the degree of fragmentation of an artificial test food after a fixed number of chewing cycles (2). Dental state $(3,4)$, bite force (5), body size (6), age (7), gender $(6,8)$, salivary flow rate (9), jaw movements (10), and temporomandibular disorders (TMD) (11) are factors that can affect masticatory performance. The inter-relationship between some of these factors (12-14) means that masticatory performance should be studied using multivariate techniques (15). Few studies have addressed the association between different factors and masticatory performance using a multiple regression analysis in a dentate population. These studies proposed models in which the percentage of variation of the masticatory performance explained by factors related to dentition or muscular force ranged from 21 to $72 \%(6,8,15-17)$. Given that not all variance of masticatory performance has been explained previously by the factors examined, the study of other factors, in combination with known factors, might provide some novel insight.
One aspect of chewing is how well the tongue and cheeks manipulate the food particles between the teeth 3 (18). In the chewing cycle, the tongue and cheeks often move rhythmically in a regular pattern along with the jaw as well as controlling pressure against the hard palate (19). During the opening phase, food is repositioned in the postcanine area from the lingual side by the tongue and from the buccal side by the buccinators muscles so that food is squeezed by the molars in the closing phase. A technique has been described to quantify the temporal relationship between the intra-oral pressure of the tongue and cheek against the first molars relative to jawclosing activity during mastication (20). However, the way in which the intra-oral force of the tongue and cheek affects masticatory performance has not been evaluated.

Various aspects of static occlusion, which refers to the occlusal contacts in maximal intercuspal position, have been related to masticatory performance, including occlusal contact area $(6,16,21)$, number of tooth contacts (17), number of functional tooth units $(3,4,15)$, and malocclusion $(7,17,21)$. Although the occlusal phase of the chewing cycle is thought to be extremely important, during mastication there are also gliding 
contacts. The length of the occlusal glide averages $1.3 \mathrm{~mm}$ during closing and $1.6 \mathrm{~mm}$ during opening (22). Furthermore, the chewing pattern is related to the type of lateral dental guidance (14). Therefore, chewing efficiency might be related to the characteristics of occlusal contacts during gliding movements (i.e. the dynamic occlusion).

The aim of this study was to determine the relationship between masticatory performance, several muscular factors, and both static and dynamic occlusal characteristics, in a population with a full or near-full complement of natural teeth by means of multiple regression analysis. The working hypothesis to be tested was that prediction of masticatory performance in dentate young adults can be enhanced by dynamic occlusal characteristics or by the force exerted using the tongue 4 and cheeks.

\section{Material and methods}

One-hundred healthy young adults (71 women and 29 men) with natural dentition were randomly selected from volunteer students and staff at the University of Barcelona Faculty of Dentistry (Barcelona, Spain) to participate in this cross-sectional study. Their ages ranged from 20.3 to $47.9 \mathrm{yr}$ and the mean age of the sample was $22.4 \mathrm{yr}$. Subjects with fewer than 24 natural teeth, those under active orthodontic treatment, or those suffering pain other than from TMD were excluded. The presence of TMD was assessed according to the Spanish version of the Research Diagnostic Criteria for TMD (23) (available at http://www.rdc-tmdin-

5 ternational.org/). Subjects were fully informed and signed the informed consent form approved by the local ethics committee (Code 03/06). All experiments were carried out in accordance with the principles of the Helsinki Declaration.

Data were collected from each subject in the following chronological order: anthropometric assessments, masticatory performance, occlusal registrations, and muscular force measurements.

\section{Muscular force measurements}

Height and body weight were measured to the nearest $1.0 \mathrm{~mm}$ and $0.1 \mathrm{~kg}$, respectively. Body mass index (BMI) was calculated using the formula [weight $(\mathrm{kg}) /$ height $\left.^{2}(\mathrm{~m})\right]$. A bite-force transducer (Gnatodynamometer; Technical 6 University of Catalonia, Spain) was used to measure unilateral forces. In order to protect the teeth, both sides of the transducer tips were covered with 1-mm-thick rubber plates attached with cyanoacrylate and covered with a latex finger cot. The vertical height of the bite fork was $20.5 \mathrm{~mm}$. This device was calibrated with loads from 0 to $1200 \mathrm{~N}$ by means of a compression test machine at the Department of Materials Science and Metallurgy of the Technical University of Catalonia. Maximum bite force was measured for five different regions: between the first molars on the right and left sides, between the first premolars on both sides, and between the central incisors. Subjects were encouraged to bite as hard as possible on the transducer for a few seconds. The five measurements were performed three times, changing the order on each occa7 sion. The highest bite force value obtained from each region (first molar, first premolar, and central incisors) was selected. The finger-thumb grip force of each hand, the tongue force against the palate, and the left and right cheek force against the buccal side of the molars were also 8 measured similarly using the bite-force transducer (Fig. 1). Thus, six values related to muscular force were obtained from each subject.
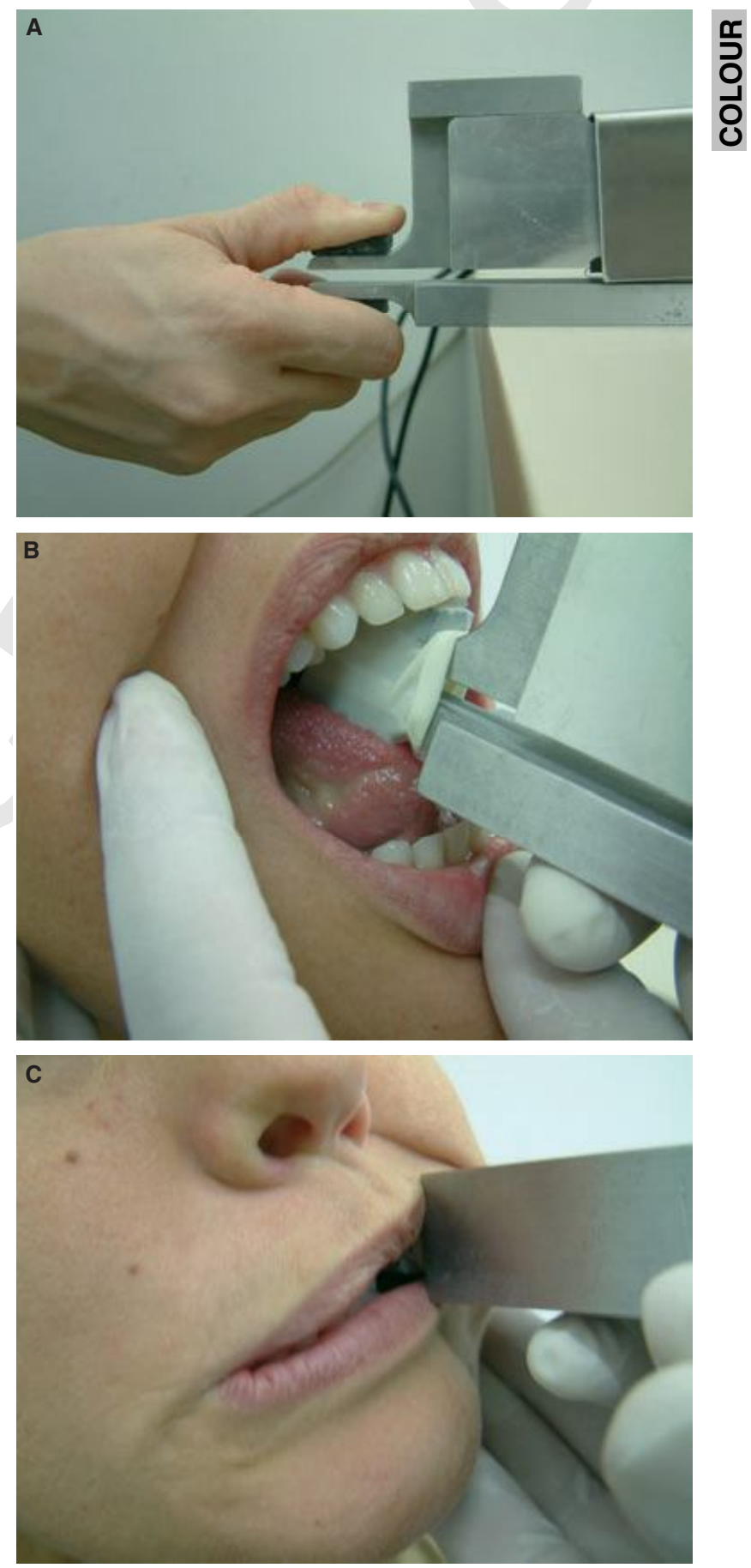

Fig. 1. Bite-force transducer (Gnatodynamometer) used in this study: Measurement of finger-thumb grip force (A), tongue force against the palate (B), and cheek force against the buccal side of the molars (C). To measure the cheek force, subjects were instructed to "compress this device against the molars as hard as you can'. 


\section{Static occlusion}

Overjet and overbite were measured to assess anteroposterior and vertical relationships of the right central incisors, by means of a digital calliper (Absolute; Vogel Germany, Kevelaer, Germany). The anteroposterior relationship of the upper and lower canines and the first molars was evaluated using Angle's classification. The transverse or buccolingual relationship of the upper and lower posterior teeth was assessed and classified into two groups: 'no posterior crossbite', and 'unilateral or bilateral crossbite'.

To measure the occlusal contact area, a bite registration material (Occlufast Rock; Zhermack, Badia Polesine, Italy) was applied to all the mandibular teeth, and subjects were asked to bite down firmly into the maximum intercuspal position (ICP) for $1 \mathrm{~min}$, until the material had set. The occlusal registration was removed and excess portions were carefully trimmed. An image of each occlusal registration was obtained by means of a scanner (HP Scanjet 5370C; Hewlett-Packard, Palo Alto, CA, USA) by placing the mandibular occlusal surface facing downwards on the scanner bed. The software program UTHSCSA IMAGE TOOL (V 3.0; University of Texas Health Science Center, San Antonio, TX, USA) was used to analyse the occlusal registrations. The image of each occlusal registration was converted into a greyscale image. Calibration was performed using a known distance measured with a digital calliper (Absolute). Pixel densities were calculated for an interocclusal distance that ranged from 0 to $500 \mu \mathrm{m}$ at $50-\mu \mathrm{m}$ increments. To establish the relationship between each of the 256 greys and the thickness of the occlusal registration, a stepped wedge of Occlufast was used and measured with a digital external micrometer (IP40; Vogel Germany). The calibration curve obtained was [thickness $(\mu \mathrm{m})=1180.592-9.537 * \mathrm{PD}$ $\left.+0.02016^{*}(\mathrm{PD})^{2}\right]$ (where PD $=$ pixel density) with a correlation coefficient of 0.998 . The occlusal area was measured in four different regions: for anterior and postcanine teeth, and for the left and right sides. The sum of these four regions was calculated. The number of anterior and posterior teeth in contact was determined where an interocclusal distance of $50 \mu \mathrm{m}$ or less counted as contact. Functional tooth units, defined as pairs of occluding postcanine teeth, were calculated from the occlusal registration at the ICP, scoring molars with an interocclusal distance of $<50 \mu \mathrm{m}$ as 92 units and premolars as 1 unit.

\section{Dynamic occlusion}

To determine the dynamic occlusal characteristics, siliconebased occlusal registrations were obtained from each subject in two jaw positions: a right lateral excursion at a $1.5 \mathrm{~mm}$ intercuspal distance from the incisal point; and a left lateral excursion at a $1.5 \mathrm{~mm}$ intercuspal distance from the incisal point. To regulate each lateral position, three marks were made on the maxillary central incisors and one mark on the mandibular central incisor by means of a template. Subjects who had difficulty performing lateral movements were guided to avoid protrusive movement. Interocclusal registrations were scanned and analysed following the same procedure as ICP registration.

Occlusal contact area and number of teeth in contact were determined in the same way as for the ICP registration. The type of dynamic occlusion pattern was assessed on both the working and non-working side, for both lateral excursions of $1.5 \mathrm{~mm}$ from ICP at $50 \mu \mathrm{m}$ thick. Lateral dental guidance was classified as anterior protected articulation, canine protection, group function, and not defined $(14,24)$. Subjects were assigned a contact pattern for the non-working side for each lateral excursion: 'absence of non-working side occlusal contacts', 'presence of non-working side occlusal contacts' or 'presence of non-working side interferences' (24).

\section{Masticatory performance}

Masticatory performance was evaluated using a standardized test food (Optosil P Plus; Heraeus Kulzer, Hanau, Germany) (6). Tablets of Optosil (5 mm thick, $20 \mathrm{~mm}$ diameter) were made as described by ALBERT et al. (25) and were cut into four quarters. Each subject chewed three quarter tablets $(2 \mathrm{~g})$ for 20 cycles. Particles from five trials $(10 \mathrm{~g})$ were dried for $24 \mathrm{~h}$ and passed through a series of eight sieves $(0.25,0.425,0.85,2,2.8,3.15,4$, and $5.6 \mathrm{~mm})$ while being shaken for $1 \mathrm{~min}$. After cumulative weight distribution of the sieves' contents had been determined, median particle size and broadness of particle distribution (essentially a measure of the distribution's slope) were calculated for each subject using the Rosin-Rammler equation $\left[\mathrm{Q}_{\mathrm{w}}(X)=1-2 \mathrm{E}-\left(X / X_{50}\right)^{b}\right] . \mathrm{Q}_{\mathrm{w}}(X)$ is the fraction of particles by weight with a diameter smaller than $X$. The median particle size $\left(X_{50}\right)$ is the size of a theoretical sieve through which $50 \%$ of the weight can pass, and $b$ describes the broadness of the particle distribution (26). The total duration of the five trials was used to calculate the duration of the average chewing cycle.

\section{Statistical analysis}

In order to evaluate the reproducibility of the parameters used in this study, 2-4 wk after the first measurements were taken, they were all repeated for nine of the subjects. Intraclass correlation coefficients and the smallest detectable difference in the main parameters were determined as measures of reliability and agreement, respectively (Table 1). Reliability relates the measurement error to the variability between subjects, and agreement assesses how close the results of the repeated measurements are by estimating the measurement error (27). The normal distribution fit of the data was tested by means of a Kolmogorov-Smirnov test. Comparisons were performed using chi-square analysis, Student's $t$-tests, Mann-Whitney $U$-tests, or analysis of variance, as appropriate. Pearson correlation coefficients were calculated to evaluate the correlation between variables and median particle size. Finally, and because variables are inter-related, a stepwise multiple linear regression analysis with an inclusion level of 0.05 was performed to examine whether variables would significantly contribute to explain the median particle size. The most significant factor (that is, the one that would result in the largest likelihood ratio) was added to the model at each step and the process was continued until no further significant contributing factor could be added. Statistical analysis was performed using the sPSS program (version 14.0.1; SPSS, Chicago, IL, USA) and $P$-values below 0.01 were considered significant.

\section{Results}

\section{Muscular force and masticatory performance}

The mean of the squared correlation coefficients $\left(R^{2}\right)$ of the least-squares method for linear fitting to the Rosin- 
Table 1

Reproducibility estimated by the intraclass correlation coefficients (ICC) with $95 \%$ confidence interval (CI) coefficients and the smallest detectable difference (SDD) for the main variables $(n=9)$

\begin{tabular}{|c|c|c|}
\hline Variable & $\begin{array}{l}\text { Intraclass } \\
\text { correlation } \\
\text { coefficients } \\
(95 \% \mathrm{CI})\end{array}$ & $\begin{array}{l}\text { Smallest } \\
\text { detectable } \\
\text { difference }\end{array}$ \\
\hline Median particle size & $0.97(0.88-0.99)$ & $0.4 \mathrm{~mm}$ \\
\hline Bite force at first molar & $0.97(0.89-0.99)$ & $136 \mathrm{~N}$ \\
\hline Bite force at first premolar & $0.98(0.89-1.0)$ & $104 \mathrm{~N}$ \\
\hline Bite force between incisors & $0.96(0.84-0.99)$ & $66 \mathrm{~N}$ \\
\hline Finger-thumb grip force & $0.96(0.81-0.99)$ & $11 \mathrm{~N}$ \\
\hline $\begin{array}{l}\text { Tongue force against } \\
\text { the palate }\end{array}$ & $0.87(0.42-0.97)$ & $9 \mathrm{~N}$ \\
\hline $\begin{array}{l}\text { Cheek force against the } \\
\text { buccal side of the molars }\end{array}$ & $0.96(0.81-0.99)$ & $6 \mathrm{~N}$ \\
\hline $\begin{array}{l}\text { Occlusal contact area } \\
(0-50 \mu \mathrm{m}) \text { at intercuspal } \\
\text { position }\end{array}$ & $0.95(0.76-0.99)$ & $16.5 \mathrm{~mm}^{2}$ \\
\hline $\begin{array}{l}\text { Occlusal contact area at } \\
\text { the left lateral } \\
\text { excursion position }\end{array}$ & $0.91(0.57-0.98)$ & $3.3 \mathrm{~mm}^{2}$ \\
\hline $\begin{array}{l}\text { Occlusal contact area } \\
\text { at the right lateral } \\
\text { excursion position }\end{array}$ & $0.97(0.86-0.99)$ & $1.0 \mathrm{~mm}^{2}$ \\
\hline
\end{tabular}

Rammler function was 0.987 [standard deviation (SD) $=$ 0.04].

The median particle size for women was significantly higher than for men (Table 2). However, there were no differences between the sexes in the broadness of particle distribution or duration of chewing cycle. Men were significantly heavier and taller than women and their BMIs were different. Pearson correlation coefficients between median particle size and variables related to body size, maximum muscular force, and masticatory performance are shown in Table 2. Median particle size was negatively correlated with all the variables related to body size and maximum muscular force, with maximum force at the first molar having the closest relationship.

Forty-one subjects had TMD and the most prevalent diagnosis of this was disc displacement with reduction. The results from analysis using the Student's $t$-test revealed no significant differences between the median particle sizes obtained for subjects with or without TMD.

\section{Static occlusal characteristics and masticatory performance}

No static occlusion parameters showed any difference between the sexes. Angle class was not significantly related to median particle size. However, subjects with a unilateral or a bilateral posterior crossbite had a higher median particle size than subjects with no crossbite $(P<0.05$; Student's $t$-test). Occlusal contact area at different cumulative thicknesses was negatively correlated with median particle size, with Pearson coefficients ranging from -0.33 to -0.41 (Table 3 ). The number of anterior teeth in contact was significantly correlated with median particle size; however, no significant correlation between functional tooth units and median particle size was found.

\section{Dynamic occlusal characteristics and masticatory performance}

While an occlusal contact area $<50 \mu \mathrm{m}$ thick at a $1.5 \mathrm{~mm}$ lateral position was negatively correlated with median particle size at the right lateral excursion $(r=-0.20 ; P=0.02)$, no significant correlation at the left lateral excursion was found $(P>0.05)$. A weak

Table 2

Comparison, by gender, of variables related to mastication, body size and maximum muscular force, and their bivariate correlation with median particle size (MPS)

\begin{tabular}{|c|c|c|c|c|}
\hline & Women $(n=71)$ & Men $(n=29)$ & Total $(n=100)$ & $\begin{array}{l}\text { Correlation coefficient } \\
\text { with MPS ( } P \text {-value) }\end{array}$ \\
\hline \multicolumn{5}{|l|}{ Masticatory performance } \\
\hline Median particle size $(\mathrm{mm})$ & $4.3(1.4)^{* * *}$ & $3.3(1.0)$ & $4.0(1.3)$ & \\
\hline Broadness & $2.7(0.2)$ & $2.7(0.2)$ & $2.7(0.2)$ & $0.38(<0.001)$ \\
\hline Chewing cycle duration (ms) & $790(137)$ & $772(123)$ & 785 (132) & $-0.10(0.16)$ \\
\hline \multicolumn{5}{|l|}{ Body size } \\
\hline Height $(\mathrm{cm})$ & $165(5.0)^{* * *}$ & $178(6.6)$ & $169(8.1)$ & $-0.23(0.01)$ \\
\hline Weight $(\mathrm{kg})$ & $59.9(7.6)^{* * *}$ & $80.3(10.4)$ & $65.8(12.6)$ & $-0.33(<0.001)$ \\
\hline $\operatorname{BMI}\left(\mathrm{kg} \mathrm{m}^{-2}\right)$ & $22.0(2.7)^{* * *}$ & $25.4(3.2)$ & $23.0(3.2)$ & $-0.27(0.003)$ \\
\hline \multicolumn{5}{|l|}{ Maximum muscular force } \\
\hline First molar $(\mathrm{N})$ & $511(130)^{* * *}$ & $740(153)$ & $578(171)$ & $-0.60(<0.001)$ \\
\hline First premolar $(\mathrm{N})$ & $360(107)^{* * *}$ & $521(125)$ & $406(134)$ & $-0.54(<0.001)$ \\
\hline Central incisors $(\mathrm{N})$ & $161(55.4)^{* * *}$ & $229(66.7)$ & $181(66)$ & $-0.42(<0.001)$ \\
\hline Finger-thumb grip (N) & $74.0(13.4)^{* * *}$ & $106.1(13.3)$ & $83.3(19.8)$ & $-0.32(0.001)$ \\
\hline Cheek (N) & $24.3(6.0)^{* * *}$ & $35.0(6.4)$ & $27.4(7.8)$ & $-0.29(0.002)$ \\
\hline Tongue $(\mathrm{N})$ & $18.9(9.3)^{* * *}$ & $26.2(9.3)$ & $21.0(9.9)$ & $-0.26(0.005)$ \\
\hline
\end{tabular}

Results are expressed as mean (standard deviation).

Differences between the sexes were determined using the Student's $t$-test. $* * * P<0.001$.

BMI, body mass index. 
Table 3

Bivariate correlation between static occlusal characteristics and median particle size (MPS)

\begin{tabular}{|c|c|c|}
\hline & Mean (SD) & $\begin{array}{c}\text { Correlation } \\
\text { coefficient } \\
\text { with MPS } \\
(P \text {-value })\end{array}$ \\
\hline Overjet (mm) & $2.7(1.4)$ & $0.05(0.31)$ \\
\hline Overbite (mm) & $2.5(1.6)$ & $-0.21(0.02)$ \\
\hline $\begin{array}{l}\text { Occlusal area }<50 \mu \mathrm{m} \\
\left(\mathrm{mm}^{2}\right)\end{array}$ & $29.0(17.7)$ & $-0.41(<0.001)$ \\
\hline $\begin{array}{l}\text { Occlusal area }<100 \mu \mathrm{m} \\
\left(\mathrm{mm}^{2}\right)\end{array}$ & $49.6(27.1)$ & $-0.41(<0.001)$ \\
\hline $\begin{array}{l}\text { Occlusal area }<150 \mu \mathrm{m} \\
\left(\mathrm{mm}^{2}\right)\end{array}$ & $61.5(31.4)$ & $-0.41(<0.001)$ \\
\hline $\begin{array}{l}\text { Occlusal area }<200 \mu \mathrm{m} \\
\left(\mathrm{mm}^{2}\right)\end{array}$ & $73.4(35.3)$ & $-0.41(<0.001)$ \\
\hline $\begin{array}{l}\text { Occlusal area }<250 \mu \mathrm{m} \\
\left(\mathrm{mm}^{2}\right)\end{array}$ & 86.9 (39.7) & $-0.40(<0.001)$ \\
\hline $\begin{array}{l}\text { Occlusal area }<300 \mu \mathrm{m} \\
\left(\mathrm{mm}^{2}\right)\end{array}$ & $102.6(44.2)$ & $-0.39(<0.001)$ \\
\hline $\begin{array}{l}\text { Occlusal area }<350 \mu \mathrm{m} \\
\left(\mathrm{mm}^{2}\right)\end{array}$ & $117.9(50.0)$ & $-0.33(<0.001)$ \\
\hline $\begin{array}{l}\text { Occlusal area }<500 \mu \mathrm{m} \\
\left(\mathrm{mm}^{2}\right)\end{array}$ & $183.3(63.2)$ & $-0.36(<0.001)$ \\
\hline Functional tooth units & $12.0(2.3)$ & $-0.08(0.22)$ \\
\hline $\begin{array}{l}\text { Number of anterior teeth } \\
\text { in contact }\end{array}$ & $3.1(2.2)$ & $-0.31(0.001)$ \\
\hline $\begin{array}{l}\text { Number of posterior teeth } \\
\text { in contact }\end{array}$ & $7.7(1.5)$ & $-0.10(0.15)$ \\
\hline Number of teeth in contact & $10.8(2.8)$ & $-0.30(0.001)$ \\
\hline
\end{tabular}

$\mathrm{SD}$, standard deviation.

correlation was observed between the number of anterior teeth in contact at the left lateral excursion and the median particle size $(r=-0.21 ; P=0.02)$. The percentage of canine protection on the left side was higher in men than in women, and subjects who had canine protection on the left side showed a lower median particle size than subjects who had no defined lateral dental guidance $[P<0.05$ analysis of variance (ANOVA) and post-hoc Duncan test]. Subjects with non-working contacts or non-working interferences did not have signifi- cantly different median particle size compared with 11 subjects who had no non-working contacts.

\section{Stepwise multiple regression analysis}

The matrix of bivariate correlations among the variables that were significantly correlated with median particle size is shown in Table 4. All muscular force parameters were significantly inter-related. No significant correlations were found between occlusal variables and maximum muscular force, except for occlusal contact area at the ICP with maximum bite force at the first molar and with cheek force. The occlusal contact area at the left lateral excursion was significantly correlated with the occlusal contact area on the other side, but no correlation was observed between the occlusal contact area at the ICP and at either lateral excursion.

Stepwise multiple regression analysis showed that the maximum bite force on the first molar, the occlusal contact area $<200 \mu \mathrm{m}$ thick at the ICP, the presence of unilateral or bilateral posterior crossbite, and the number of anterior teeth in contact at the ICP $(P<0.001)$, were the most important factors affecting median particle size (Table 5). These four variables accounted for $45 \%$ of the variation in masticatory performance (adjusted $R^{2}=0.45$ ). Bite force on the first molar explained $36 \%$ of the variation in masticatory performance (Fig. 2). The addition of occlusal contact area, the presence of crossbite, and the number of anterior teeth in contact at the ICP to bite force explained an additional $9 \%$ of the variation of masticatory performance.

\section{Discussion}

Maximum bite force in the region of the first molar has the best correlation with masticatory performance in a young adult population with a full or near-full complement of natural teeth and explains $36 \%$ of its variation. Static occlusion characteristics such as occlusal contact area, the presence of posterior crossbite, and the number of anterior teeth in contact explained an additional $9 \%$

Table 4

Bivariate correlation coefficients among variables

\begin{tabular}{|c|c|c|c|c|c|c|c|c|c|c|}
\hline & 1 & 2 & 3 & 4 & 5 & 6 & 7 & 8 & 9 & 10 \\
\hline \multicolumn{11}{|l|}{ 1. MPS } \\
\hline 2. Gender ${ }^{\dagger}$ & $-0.35 * * *$ & & & & & & & & & \\
\hline 3. Weight & $-0.33 * * *$ & $0.74 * * *$ & & & & & & & & \\
\hline 4. Force, 1st molar & $-0.60 * * *$ & $0.61 * * *$ & $0.46 * * *$ & & & & & & & \\
\hline 5. Finger-thumb grip & $-0.32 * * *$ & $0.74 * * *$ & $0.71 * * *$ & $0.58 * * *$ & & & & & & \\
\hline 6. Force, cheek & $-0.29 * *$ & $0.63 * * *$ & $0.54 * * *$ & $0.63 * * *$ & $0.58 * * *$ & & & & & \\
\hline 7. Force, tongue & $-0.26 * *$ & $0.34 * * *$ & $0.36 * * *$ & $0.42 * * *$ & $0.41 * * *$ & $0.58 * * *$ & & & & \\
\hline 8. Overbite & $-0.21 *$ & -0.02 & -0.14 & 0.13 & -0.11 & -0.08 & -0.08 & & & \\
\hline 9. Occlusal area ICP & $-0.41 * * *$ & 0.10 & 0.04 & $0.36 * * *$ & 0.08 & $0.18^{*}$ & 0.16 & 0.15 & & \\
\hline 10. Occlusal area RLP & $-0.20^{*}$ & 0 & -0.02 & 0.14 & -0.05 & -0.03 & 0.03 & -0.08 & 0.11 & \\
\hline 11. Occlusal area LLP & -0.02 & 0 & 0.12 & -0.02 & -0.02 & 0.02 & 0.06 & -0.05 & 0.02 & $0.38 * * *$ \\
\hline
\end{tabular}

ICP, intercuspal position; LLP, left lateral position; MPS, median particle size; RLP, right lateral position.

$* P<0.05 ; * * P<0.01 ; * * * P<0.001$.

0 women; 1 man. 
Table 5

Stepwise regression models of factors related to median particle size

\begin{tabular}{|c|c|c|c|c|c|c|}
\hline Model & Variables entered & Constant & Beta & $R$ & $R_{\mathrm{a}}^{2}$ & F (Sig.) \\
\hline & Maximum bite force at first molar (N) & 6.780 & -0.004 & 0.60 & 0.36 & $56.1(<0.001)$ \\
\hline 2 & Occlusal contact area $(<200 \mu \mathrm{m})$ at ICP $\left(\mathrm{mm}^{2}\right)$ & 7.169 & -0.007 & 0.65 & 0.41 & $35.8(<0.001)$ \\
\hline 3 & Lateral crossbite $(0=$ absence; $1=$ presence $)$ & 7.065 & 0.66 & 0.67 & 0.44 & $26.5(<0.001)$ \\
\hline 4 & Number of anterior teeth in contact at ICP & 7.199 & -0.09 & 0.69 & 0.45 & $21.5(<0.001)$ \\
\hline
\end{tabular}

16.ICP, intercuspal position; F (Sig.); $R$, correlation coefficient; $R_{\mathrm{a}}{ }^{2}$.

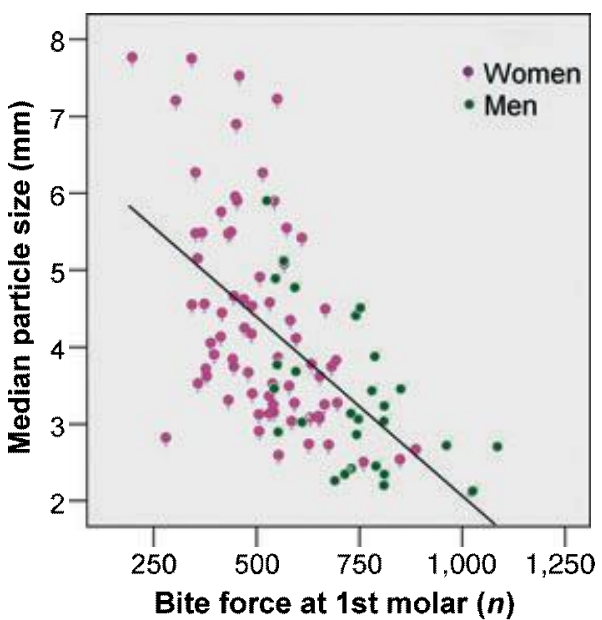

Fig. 2. Correlation between median particle size and maximum bite force at the first molar region by gender of subjects. MPS $=6.78-0.004^{*}$ BF. $R_{\mathrm{a}}{ }^{2}=0.36 . P<0.001$. BF, maximum bite force at first molar (N); MPS, median particle size $2(\mathrm{~mm}) ; R_{\mathrm{a}}{ }^{2}$.

of the variation in masticatory performance. No variable related to dynamic occlusion or tongue or cheek force emerged as key predictors in the multivariate regression model. HATCH et al. (15) reported that the number of functional units and bite force explained $68 \%$ of the variability in masticatory performance. JULIEN et al. (6) found that weight and occlusal contact area could explain $72 \%$ of the individual differences in masticatory performance. However, these studies were performed in a more heterogeneous population including either children and young adults or subjects with some loss of postcanine teeth, with a mean of 8.4 (SD 3.8) functional tooth units. In our sample, subjects had a mean of 12.0 (SD 2.3) functional tooth units, and $91 \%$ of the subjects were between 20 and $29 \mathrm{yr}$ of age. VAN DER BILT \& FonTIJN-TEKAMP (2) found that functional tooth units explained $16 \%$ of masticatory performance in a rather homogeneous dentate sample with a mean of 10.9 (SD 2.4) units.

The moderate correlation between maximum bite force and masticatory performance we observed is in accordance with previous studies that analyzed different test foods in a dentate population $(5,15,28)$. Although tongue force against the palate and cheek force against the buccal side of the molars were significantly correlated with masticatory performance, this correlation became insignificant in the stepwise multiple regression analysis after controlling for maximum bite force at the first molar. Therefore, the force of the tongue and cheeks seem not to be key predictors of masticatory performance. Further studies are needed to clarify the influence of the tongue and the cheeks on masticatory performance.

Our mean occlusal contact area (up to $50 \mu \mathrm{m}$ of interocclusal distance) at the ICP $-29 \mathrm{~mm}^{2}-$ is in agreement with data reported by Yurkstas \& MANLY (29). However, other studies reported very different values $(6$, 21,30 ), ranging from 4 to $64 \mathrm{~mm}^{2}$. Different populations and methods used in these studies could explain these important differences. Our correlation coefficient between the occlusal contact area and masticatory performance -0.41 - is in agreement with that reported by OwENs et al. (21) using a similar method. Because occlusal contact area is positively correlated with maximum bite force (Table 4), in agreement with other studies $(12,30)$, the weak correlation between occlusal contact area and masticatory performance was attenuated in the stepwise multiple regression analysis after controlling for maximum bite force at first molar. Therefore, the occlusal contact area at the ICP should not be used alone to predict masticatory performance in a young adult population with a full or near-full complement of natural teeth (21).

As expected, no significant correlation between the number of functional postcanine tooth units and masticatory performance was observed because the sample of subjects was very homogeneous with complete or nearcomplete dentition. However, in this population the number of anterior teeth in contact at the ICP was variable, in agreement with other studies $(31,32)$, and the number of anterior teeth in contact was positively correlated with masticatory performance and was found to be another key predictor in our model. This suggests that anterior teeth in contact at the ICP in a complete dentate population can exert a functional role in mastication. The presence of posterior crossbite was associated with a lower masticatory performance. One explanation for this could be that subjects with a unilateral posterior crossbite had a shorter contact glide distance, as reported recently (33). We found no significant differences in bite force between subjects with and without posterior crossbite, in contrast to the findings of a previous study with pre-orthodontic children (34). 
Some dynamic occlusion parameters showed a weak, but significant, correlation with masticatory performance. However, no variables related to dynamic occlusion emerged as key predictors in our multivariate regression model. This lack of correlation could be because mastication of this type of test food depends more on static occlusion than on dynamic occlusion. Another explanation could be that the length of the occlusal glide during chewing, of $1.5 \mathrm{~mm}$, is an average figure and a large variation was observed within and between subjects (22). The presence of non-working side contacts was found in approximately $50 \%$ of the subjects, in accordance with previous studies $(35,36)$, and was not associated with masticatory performance. Unexpectedly, subjects with non-working side interferences did not show a significantly lower masticatory performance than the other subjects. However, the percentage of subjects with non-working side interferences was low and there may be a lack of statistical power.

The differences between the sexes observed regarding masticatory performance were in agreement with the results of previous studies in a dentate population $(6,8)$. However, other studies did not find any differences between the sexes in median particle size $(4,7,15)$. In fact, because women tended to have lower maximum force values than men, gender did not enhance the prediction of masticatory performance in the stepwise multiple regression analysis after controlling for maximum bite force at the first molar.

Our study has several limitations. First, only one test food was used to measure the masticatory performance, so the results are applicable to only one type of food. Furthermore, because subjects are being studied and they have to count their chewing cycles, mastication becomes a voluntary instead of a semi-automatic act. Recorded maximum bite force may not correspond to actual maximum muscular potential because of the increase of interincisal distance of around $20 \mathrm{~mm}$. However, this was similar for all the subjects and these values can be useful in comparing groups and correlations with masticatory performance. The method was chosen in order to make it comparable with other studies. Nevertheless, one limitation of this method is that only the first phase of food comminution is studied, so only the comminution of large particles is measured (37). Therefore, in this first phase the influence of occlusal factors may be small, and future research would focus on the effect of static and dynamic occlusion on the comminution of smaller particles.

When a fixed prosthodontic restoration is required to replace lost occlusal surfaces or missing teeth, it should replicate the existing occlusal pattern. However, this pattern can be lost either by excessive wear or because of missing teeth. Our results suggest that, in order to provide patients with the best masticatory performance, fixed prosthodontic restorations should achieve the maximum occlusal contact area up to $200 \mu \mathrm{m}$ thick and the maximum number of anterior teeth in contact at the ICP, avoiding a posterior crossbite. However, our results do not suggest any pattern of tooth contacts in eccentric mandibular positions. Generally, canine guidance is much easier to reproduce than group function $(38,39)$.
Acknowledgments - We are very grateful to the subjects for their kind cooperation in this study. This research received partial funding from the Bellvitge Campus Research Committee, University of Barcelona (ACESB 06/ 16). The authors wish to thank Dr Aleix Mestre of the Department of Materials Science and Metallurgy, Technical University of Catalonia, for technical assistance with the gnatodynamometer, and Juan Ballesteros of Internacional Ventur, S.A. for generously providing Occlufast Rock.

\section{References}

1. FeINE JS, Lund JP. Measuring chewing ability in randomized controlled trials with edentulous populations wearing implant prostheses. J Oral Rehabil 2006; 33: 301-308.

2. VAN DER BILt A, FontiJn-TeKamp FA. Comparison of single and multiple sieve methods for the determination of masticatory performance. Arch Oral Biol 2004; 49: 155-160.

3. van der Bilt A, Olthoff LW, Bosman F, Oosterhaven SP. The effect of missing postcanine teeth on chewing performance in man. Arch Oral Biol 1993; 38: 423-429.

4. Fontijn-Tekamp FA, van der Bilt A, Abbink JH, Bosman F. Swallowing threshold and masticatory performance in dentate adults. Physiol Behav 2004; 83: 431-436.

5. Fontijn-Tekamp FA, Slagter AP, Van Der Bilt A, Van 'T Hof MA, Witter DJ, Kalk W, JANSEN JA. Biting and chewing in overdentures, full dentures, and natural dentitions. J Dent Res 2000; 79: 1519-1524.

6. Julien KC, Buschang PH, Throckmorton GS, Dechow PC. Normal masticatory performance in young adults and children. Arch Oral Biol 1996; 41: 69-75.

7. Toro A, Buschang PH, Throckmorton G, Roldan S. Masticatory performance in children and adolescents with Class I and II malocclusions. Eur J Orthod 2006; 28: 112-119.

8. Akeel R, Nilner M, Nilner K. Masticatory efficiency in individuals with natural dentition. Swed Dent J 1992; 16: 191-198.

9. Ikebe K, Matsuda K, Moril K, Furuya-Yoshinaka M, NoKUBI T, RENNER RP. Association of msticatory performance with age, posterior occlusal contacts, occlusal force, and salivary flow in older adults. Int J Prosthodont 2006; 19: 475-481.

10. Ow RK, Carlsson GE, Karlsson S. Relationship of masticatory mandibular movements to masticatory performance of dentate adults: a method study. J Oral Rehabil 1998; 25: 821829.

11. Peroz I, Tai S. Masticatory performance in patients with anterior disk displacement without reduction in comparison with symptom-free volunteers. Eur J Oral Sci 2002; 110: 341344.

12. Hidaka O, Iwasaki M, Saito M, Morimoto T. Influence of clenching intensity on bite force balance, occlusal contact area, and average bite pressure. J Dent Res 1999; 78: 1336-1344.

13. Kogawa EM, Calderon PS, Lauris JR, Araujo CR, Conti PC. Evaluation of maximal bite force in temporomandibular disorders patients. J Oral Rehabil 2006; 33: 559-565.

14. Salsench J, Martinez-Gomis J, Torrent J, Bizar J, Samso J, Peraire M. Relationship between duration of unilateral masticatory cycles and the type of lateral dental guidance: a preliminary study. Int J Prosthodont 2005; 18: 339-346.

15. Hatch JP, Shinkai RS, Sakai S, Rugh JD, Paunovich ED. Determinants of masticatory performance in dentate adults. Arch Oral Biol 2001; 46: 641-648.

16. Wilding RJ. The association between chewing efficiency and occlusal contact area in man. Arch Oral Biol 1993; 38: 589-596.

17. Henrikson T, Ekberg EC, Nilner M. Masticatory efficiency and ability in relation to occlusion and mandibular dysfunction in girls. Int J Prosthodont 1998; 11: 125-132.

18. van der Bilt A, Engelen L, Pereira LJ, van der Glas HW, AbBink JH. Oral physiology and mastication. Physiol Behav 2006; 89: 22-27. 
19. Hori K, Ono T, Nokubi T. Coordination of tongue pressure and jaw movement in mastication. $J$ Dent Res 2006; 85: 187191.

20. Casas MJ, Kenny DJ, Macmillan RE. Buccal and lingual activity during mastication and swallowing in typical adults. J Oral Rehabil 2003; 30: 9-16.

21. Owens S, Buschang PH, Throckmorton GS, Palmer L, ENGLISH J. Masticatory performance and areas of occlusal contact and near contact in subjects with normal occlusion and malocclusion. Am J Orthod Dentofacial Orthop 2002; 121: 602609.

22. Hayasaki H, Sawami T, Saitoh I, Nakata S, Yamasaki Y, NAKATA M. Length of the occlusal glide at the lower incisal point during chewing. J Oral Rehabil 2002; 29: 1120-1125.

23. Dworkin SF, LeResche L. Research diagnostic criteria for temporomandibular disorders: review, criteria, examinations and specifications, critique. J Craniomandib Disord 1992; 6: 301-355.

24. The Academy of Prosthodontics. The glossary of prosthodontic terms. J Prosthet Dent 2005; 94: 10-92.

25. Albert TE, Buschang PH, Throckmorton GS. Masticatory performance: a protocol for standardized production of an artificial test food. J Oral Rehabil 2003; 30: $720-722$.

26. Olthoff LW, van der Bilt A, Bosman F, Kleizen HH. Distribution of particle sizes in food comminuted by human mastication. Arch Oral Biol 1984; 29: 899-903.

27. de Vet HC, Terwee CB, Knol DL, Bouter LM. When to use agreement versus reliability measures. J Clin Epidemiol 2006; 59: 1033-1039.

28. Engelen L, Fontijn-Tekamp A, van der Bilt A. The influence of product and oral characteristics on swallowing. Arch Oral Biol 2005; 50: 739-746.

29. Yurkstas A, Manly RS. Measurement of occlusal contact area effective in mastication. Am J Orthod 1949; 35: 185-195.
30. Gurdsapsri W, Ai M, Baba K, Fueki K. Influence of clenching level on intercuspal contact area in various regions of the dental arch. J Oral Rehabil 2000; 27: 239-244.

31. Witter DJ, Creugers NH, Kreulen CM, de HaAn AF. Occlusal stability in shortened dental arches. J Dent Res 2001; 80: $432-436$

32. Sarita PT, Kreulen CM, Witter DJ, van't Hof M, CreuGERS NH. A study on occlusal stability in shortened dental arches. Int J Prosthodont 2003; 16: 375-380.

33. Rilo B, Silva JL, Mora MJ, Cadarso-Suarez C, Santana U. Unilateral posterior crossbite and mastication. Arch Oral Biol 2007; 52: 474-478.

34. Sonnesen L, Bakke M, Solow B. Bite force in pre-orthodontic children with unilateral crossbite. Eur J Orthod 2001; 23: 741749.

35. Ingervall B, Hähner R, Kessi S. Pattern of tooth contacts in eccentric mandibular positions in young adults. $J$ Prosthet Dent 1991; 66: 169-176.

36. Bernhardt O, Gesch D, Look JO, Hodges JS, Schwahn C, MAck F, Kocher T. The influence of dynamic occlusal interferences on probing depth and attachment level: results of the Study of Health in Pomerania (SHIP). J Periodontol 2006; 77: 506-516.

37. van der Bilt A, Olthoff LW, van der Glas HW, van deR Weelen K, Bosman F. A mathematical description of the comminution of food during mastication in man. Arch Oral Biol 1987; 32: 579-586.

38. Bartlett D. Occlusion - time to reflect? A personal view. J Oral Rehabil 2005; 32: 464-466.

39. Caro AJ, Peraire M, Martinez-Gomis J, Anglada JM, SAMso J. Reproducibility of lateral excursive tooth contact in a semi-adjustable articulator depending on the type of lateral guidance. J Oral Rehabil 2005; 32: 174-179. 